\title{
Knowledge, Attitudes, and Behavior of Teenagers Regarding Sex in the Community of Los Baños, Laguna
}

\author{
Maria Eleanor L. Candelaria, ${ }^{1}$ Maricar B. Rodriguez, ${ }^{2}$ Robbie Jun B. Reyes, ${ }^{3}$ \\ Leah Rebecah R. Clemente-Co ${ }^{4}$ and Reymund D. Tatel ${ }^{2}$ \\ ${ }^{1}$ Institute of Health Policy and Development Studies, National Institutes of Health, University of the Philippines Manila \\ ${ }^{2}$ College of Public Health, University of the Philippines Manila \\ ${ }^{3}$ Department of Family and Community Medicine, Philippine General Hospital, University of the Philippines Manila \\ ${ }^{4}$ Department of Medical Technology, Far Eastern University, Manila
}

\begin{abstract}
Background. The steady rise in the number of teenage pregnancies in Los Baños, Laguna was identified as a public health concern that needs to be addressed immediately given the numerous complications to the teenage mother and her infant.
\end{abstract}

Methods. The study used a multicomponent strategy which included 1) a survey of Grades 7-12 students, 2) training of midwives, and 3) advocacy for parents to enhance existing projects on teenage pregnancy.

Results. The survey showed that students value the opinion of friends of the same gender but prefer to get information from a health professional.

Conclusion. The students did not see their parents as a preferred source of information for sexual health. Approximately one-third of the respondents mistakingly believed that teenagers will never get pregnant during their first sexual encounter. Recommendations include training teachers to provide professional advice, inclusion of more schools for the survey, further training on other counselling techniques, and extension of advocacy to other pertinent sectors of the community.

Key Words: teenage pregnancy, public health, community engagement, sexual knowledge, sexual attitude, sexual behavior

\section{INTRODUCTION}

Corresponding Author: Maria Eleanor L. Candelaria, RN Institute of Health Policy and Development Studies National Institutes of Health

University of the Philippines Manila

623 Pedro Gil Street, Ermita, Manila 1000, Philippines

Telefax: +632 3543832

E-mail: mariaeleanorcandelaria@gmail.com
The Municipal Health Office (MHO) of Los Baños, Laguna, Philippines identified the steady rise in teenage pregnancies in the municipality as a public health situation that should be immediately addressed. For the year 2017, there were a total of 348 teenage pregnancies; the youngest reported case was that of a 13-year old. Among the pregnant women with four or more prenatal visits, $24 \%$ of them were teenagers. ${ }^{1}$ This raises a serious alarm since infants born to teenage mothers are associated with lower birthweights and are less likey to receive proper nutrition. ${ }^{2}$ Teenage mothers are also less likely to access prenatal care from health professionals compared to older women due to social stigma associated with unplanned pregnancies. Premature labor is also higher among teenaged mothers.

There have been past and ongoing projects focusing on adolescent health, including reproduction health caravan, and the Youth-on-the-Go program, yet the number of teenage pregnancies has not gone down. To reduce the teenage pregnancy rate by $5 \%$ annually, the authors of this paper and the $\mathrm{MHO}$ of Los Baños augmented the existing program 
by implementing the following: 1) conducting a survey on knowledge, attitudes, and behavior related to teenage pregnancy of Grades 7-12 students in Los Baños;2) providing primary care-based training on adolescent health counselling to midwives and nurses; and 3) engaging in advocacy activities on teenage pregnancy with the community organizations.

Program data showed that the number of teenage pregnancies increased by a large number in 2010, and remained high over the following years (Figure 1). From the 184 cases in 2009, it increased by 133 in 2010. It further increased in 2011 by 54 , and has been increasing by around 20.5 for the next 6 years. Figure 1 shows the trend of teenage pregnancies in the municipality over the past nine years.

The MHO through the program manager of the Adolescent Health Development Program devised strategies to address the problem. The "Youth-on-the-Go" program was designed to create a pool of peer-educators among high school students in the municipality. The program manager developed information materials that the peer educators can use in teaching their classmates and peers on topics related to sexual health and teenage pregnancy. Advocacy campaigns in the form of pageants were also conducted to raise awareness about adolescent health issues including teenage pregnancy and HIV AIDS.
However, the key informant interviews generated information that there was a need to update the materials used for information dissemination and awareness campaigns. A concern was surfaced regarding information from the internet and other sources that may have an influence on the knowledge, attitudes, and behavior of teenagers towards teenage pregnancy.

To address this concern in the municipality, a descriptive survey was implemented to collect primary data on sociodemographic and economic factors related to teenage pregnancies and to measure the knowledge, attitudes, and behavior of Grades 7-12 students in Los Baños National High School (LBNHS). Results from this survey were then presented to the Municipal Health Officer and RHU staff in a roundtable validation meeting.

\section{Research Question}

The purpose of the survey was to provide recommendations in developing appropriate interventions on prevention of teenage pregnancy. One of the identified behaviors related to the problem was the early initiation to sex of adolescents as conceptualized in Figure 2. Therefore, the survey sought to answer the question: What are the

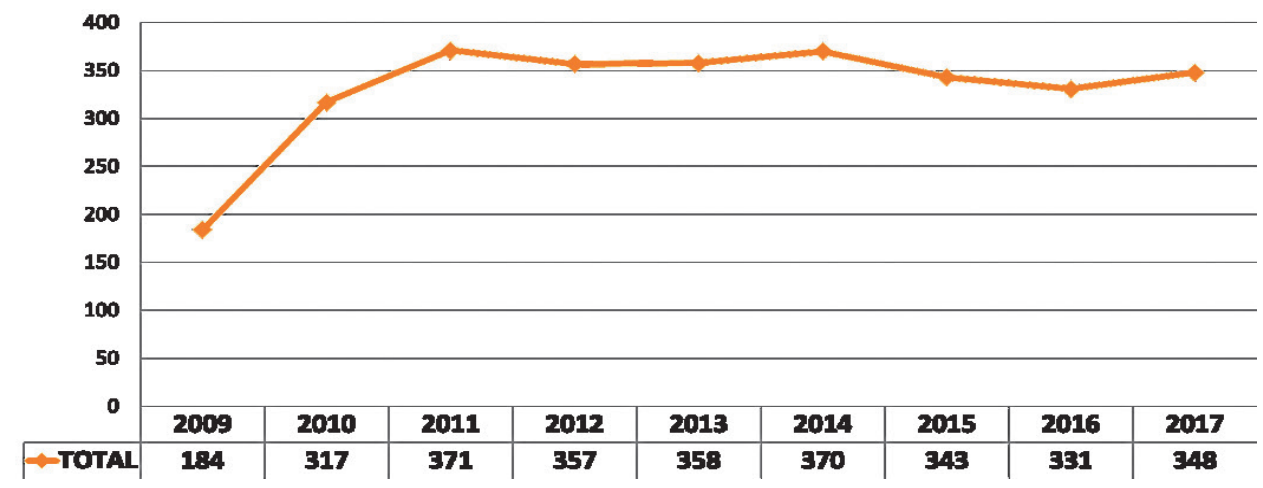

Figure 1. Frequency of teenage pregnancies in Los Baños from 2009 to 2017.

\section{Descriptive Survey}

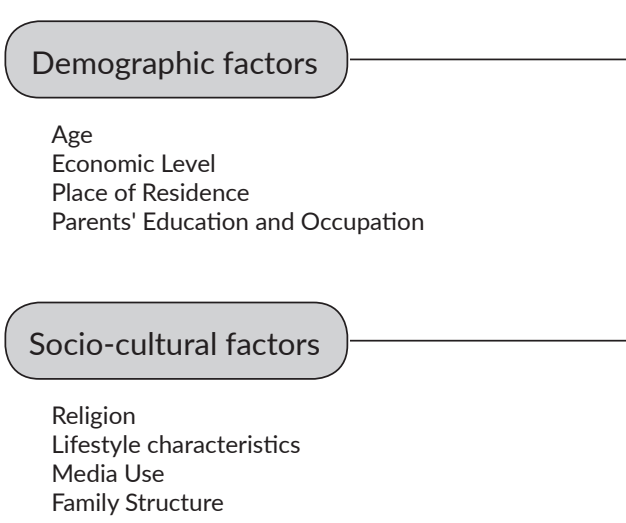

Predisposing factors

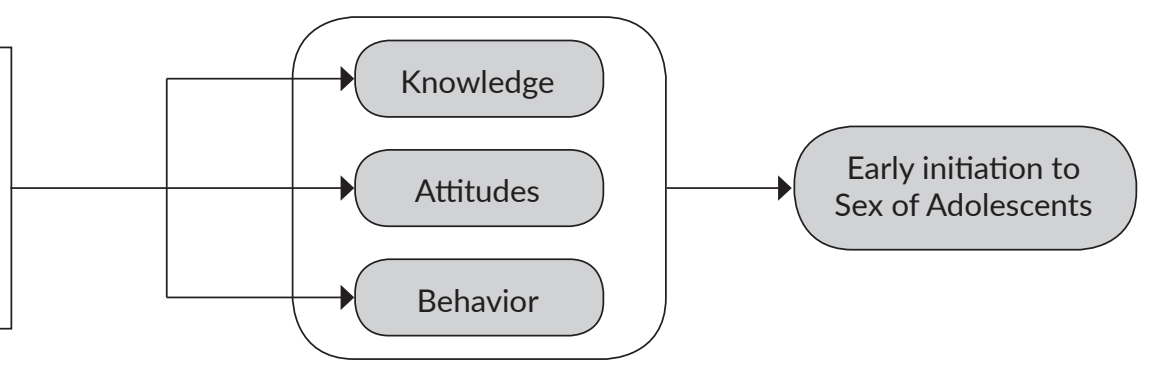

Figure 2. A conceptual framework on the predisposing factors associated with the early initiation to sex of adolescents. 
predisposing factors of the target behavior or the sociocultural and economic factors, and knowledge, attitudes, and behavior toward sexual health of Grades 7 to 12 students in LBNHS?

\section{Objective}

To determine the predisposing factors related to sexual practices among Grades 7-12 students in LBNHS. Hence, the descriptive survey specifically aimed to:

1. Determine their socio-cultural and demographic profile

2. Measure their level of knowledge, attitudes, and behavior (KABs) toward sexual health

\section{Survey Design}

The researchers conducted a descriptive survey employing a multi-stage sampling design described in Table 1. Researchers coordinated with the Department of Education district officer, principals of LBNHS Batong Malake and Bayog, and the Guidance Counselor.

Table 1. Multi-stage sampling design in LBNHS

\begin{tabular}{cc}
\hline Sampling Unit & Sampling Design \\
\hline School & Purposive sampling \\
Grade level & Stratified sampling \\
Section & Systematic Random Sampling \\
Student & Cluster Sampling \\
\hline
\end{tabular}

Table 2. Sample size computation

\begin{tabular}{cccc} 
& \multicolumn{3}{c}{ Total Population } \\
\cline { 2 - 4 } $\begin{array}{c}\text { Confidence Level } \\
(\%)\end{array}$ & $\begin{array}{c}\text { High School } \\
(4,452)\end{array}$ & $\begin{array}{c}\text { Senior High } \\
\text { School (193) }\end{array}$ & $\begin{array}{c}\text { HS+SHS } \\
(4,645)\end{array}$ \\
\cline { 2 - 4 } & \multicolumn{3}{|c}{ Sample Size } \\
\hline 90 & 256 & 113 & 369 \\
\hline
\end{tabular}

A sampling frame containing the list of grade levels and sections from high school and senior high school was utilized. Both male and female students from selected sections were all included. Having a total population of 4,645 , the computed sample size was determined through OpenEpi. A sample size of 256 and 113 participants were determined, according to a $90 \%$ confidence level.

\section{Data Collection}

\section{Development of Survey Tool}

A survey questionnaire form was developed in Tagalog. Construction of the survey questionnaire was done following the process in Figure 3. Research questions were adapted from a study among university students by De Jose $(2013)^{3}$ that targets this issue as well. Inclusion and exclusion of questions on the KABs were done through a decision matrix with stakeholders with the criteria: relevance to the objectives, ability to generate new insights, ageappropriateness, and clarity. The top 10 rated statements for each KABs item were then included.

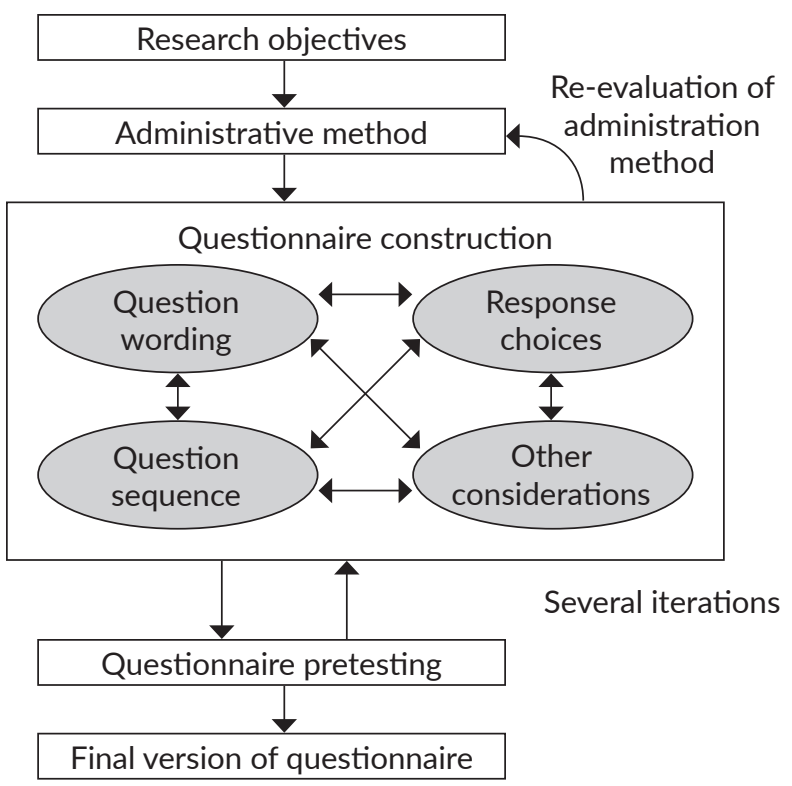

Figure 3. Survey Questionnaire Construction (Nicolaos Synodinos, 2003).

\section{Pre-testing of Survey Tools}

Prior to data collection, a pre-testing was conducted in Mayondon NHS, with a sample size of 8 , with the same criteria for the data collection. This procedure aimed to check for face validity in wording of questions and statements as well as to identify lack of clarity from instructions. The students were asked to answer the questionnaire following the instructions on the form and were given 20 minutes to answer the questionnaire.

All the students returned the completed questionnaire form before the allotted time was over. Each student was then interviewed based on how they understood each question from the form. The insights generated from the pre-testing were used to improve the questionnaire.

\section{Ethical Considerations}

Informed consent and assent forms were distributed to the schools two days before the survey. Confidentiality and anonymity were ensured. The names of the students and other identifying information were not collected during the entire implementation. The participants were oriented with the nature and purpose of the study as written in the consent and assent forms. Students were given the option to withdraw from the survey at any point without consequences.

\section{Data Processing}

The independent variables were identified from the survey tool: socio-demographic profile, activities relating to health, and family situation. The dependent variables were the following: knowledge, attitudes, and behavior related to sexual practices. All the data collected were encoded and analyzed using Epi Info 3.5.4. Data visualizations were designed using Microsoft Office Excel 360. 


\section{Limitations of the Study}

The sample was limited to public high school students. Students from private schools may have different perspectives from government students. During data collection, several consent and assent forms were not signed by parents, forgotten, or misplaced by students which affected the response rate.

\section{RESULTS AND DISCUSSION}

\section{Descriptive survey on KABs towards sexual health among Grades 7 to 12 LBNHS students}

\section{Demographics}

A total of 111 respondents participated in the survey; response rate was 30\% (Figure 4). The number of respondents was limited by the number of consent forms that were returned with approval from the parents of the underaged students.

The respondents ranged from 11 to 19 years old and most of the respondents were aged 14 . There were more female respondents (65\%) compared to males (35\%). Most of the respondents (83\%) were from rural barangays of the municipality (Figure 5). The respondents from urban barangays, Batong Malake, Baybayin, and Timugan, were less represented (17\%).

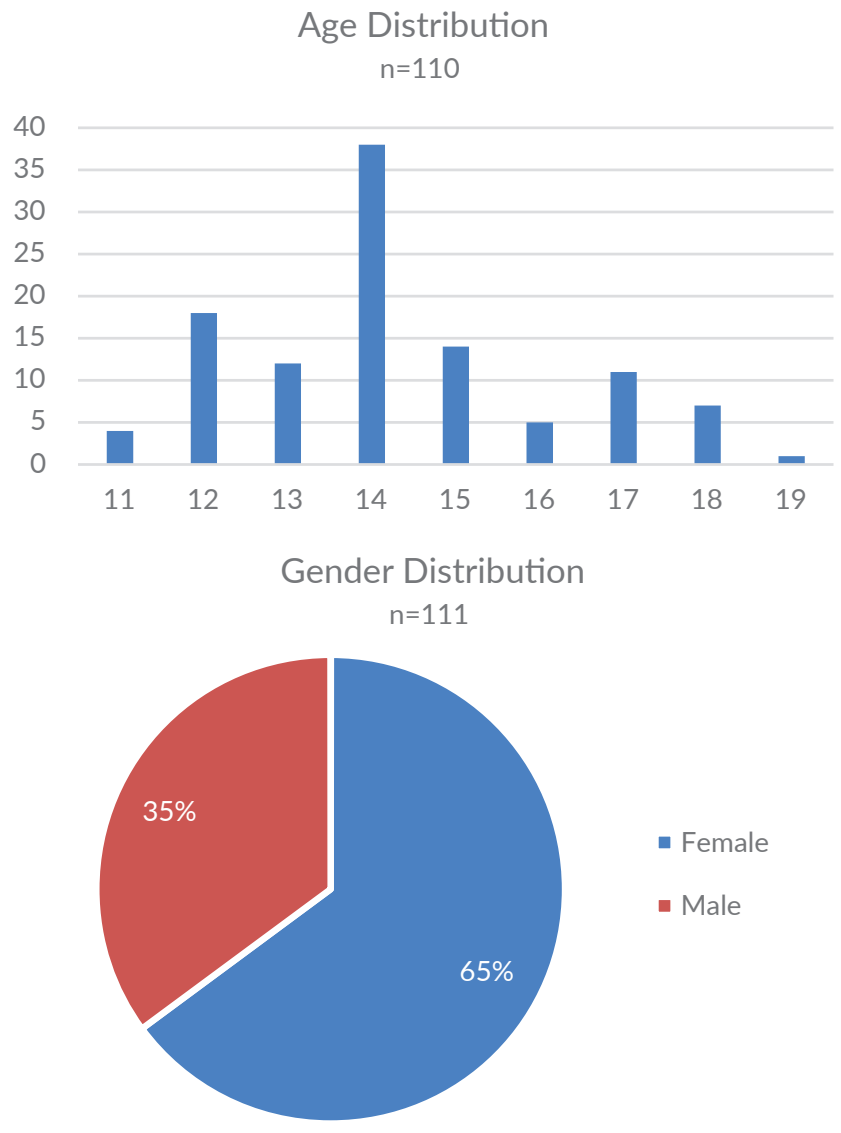

Figure 4. Age and gender distribution of participants.

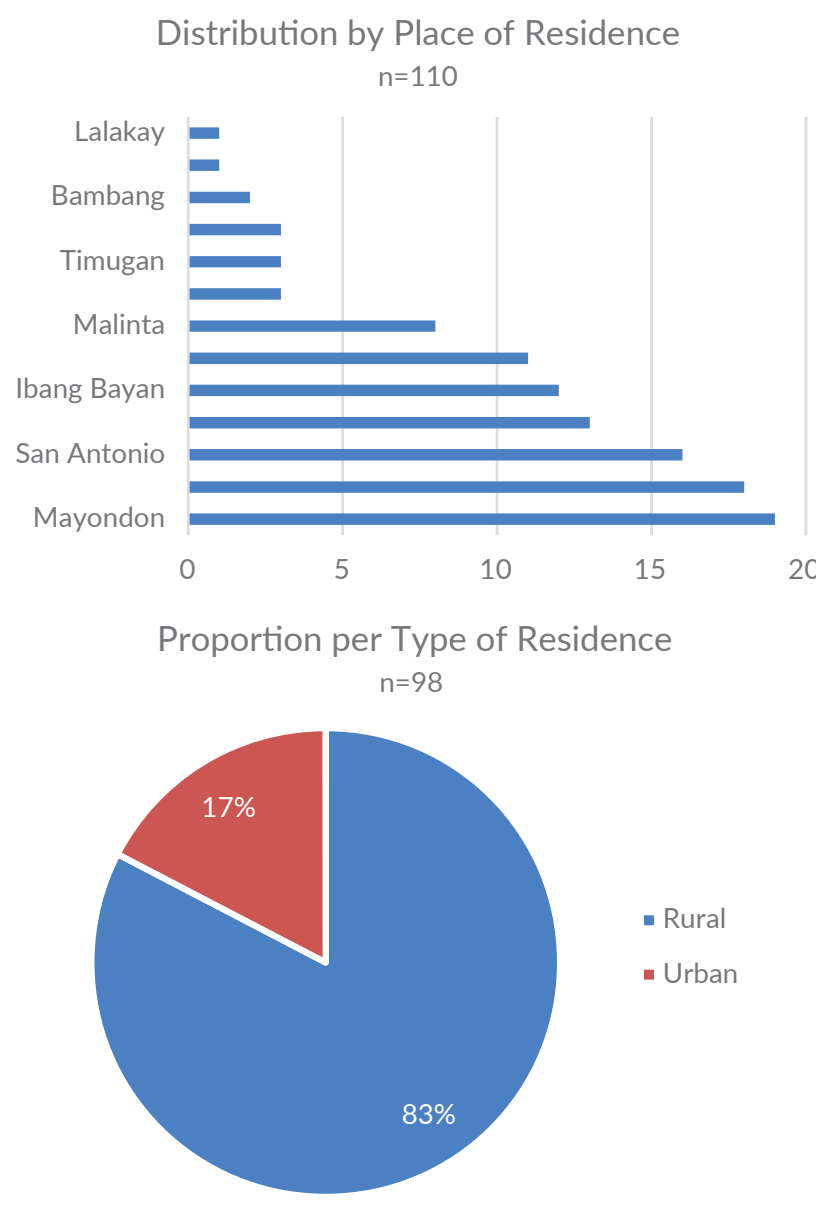

Figure 5. Distribution of respondents by place and type of residence.

\section{Social Support}

The question on social activities gathered a diverse response from the students (Figure 6). However, most of the students answered that they often have support from peers and they spent time with their families.

The question for the sources of information on sexual health was designed as a check box. The items shown on Figure 7 are the options for the students to choose from. The most common response from the students was "Kaibigan na pareho ng kasarian" (Friend of the same sex). This information varied from the results of the study by Irala et al. in 2009, where respondents value the opinion of parents more than friends. ${ }^{4}$ However, a more recent study in 2014 conducted by Baheiraei et al. showed that students refer mainly to same-sex friends and mothers specifically for sexual health information. ${ }^{5}$ The results are also similar to the studies conducted by Castilla et al in 2001 where the least common source of information was doctors. ${ }^{6}$

The respondents of the survey were also asked to choose their preferred source of information from a list (Figure 8). The most frequent responses were "Mula sa mga doktor, nars, o midwife" (From doctors, nurses, or midwives) and "Internet." The responses to the question supports the 
results of the Young Adult Fertility and Sexuality Survey (YAFS, 2013) where Internet use, and owning social media accounts, is common among CALABARZON youth. ${ }^{7}$

\section{Knowledge, Attitudes, and Behavior}

When asked about the perceived causes of teenage pregnancies, the most common response from the students were "Kakulangan sa gabay ng magulang" (Lack of guidance from parents) followed by "Panonood ng porn" (Watching porno), and "Pagiging curious at pag eexperimento" (Being curious) as shown in Figure 9.

The knowledge of the students about teenage pregnancy was measured using 8 questions (Figure 10). The questions were generated from the contents of the information materials developed by the Adolescent Health Program of the municipality. About a third of the respondents gave the wrong answers for the items "Ang isang teenager ay walang posibilidad na mabuntis sa unang pagkakataon $n g$ pakikipagtalik" (It is not possible for a teenaged girl to get pregnant during the first sexual encounter) and "Ang sanggol na ipapanganak $n g$ isang teenager ay may mas mataas na posibilidad na maging abnormal o mamatay sa panganganak" (There is a higher possibility for an infant of a teenaged mother to be abnormal or die).

The attitude of the respondents was measured using a Likert scale for agreement to situational questions (Figure 11). The results show that holding hands and hugging are considered acceptable for the respondents.

The questions to measure behavior towards teenage pregnancy were related to sex and early initiation to relationships and sex. The respondents were asked to choose from a four-point scale whether they were able to perform the activities or not. Most of the respondents answered "Hindi, bindi ko gagawin" (I will not perform) to all the questions. However, the question on the use of contraceptives had the same response from the students (Figure 12).

\section{Distribution of Social Activities}

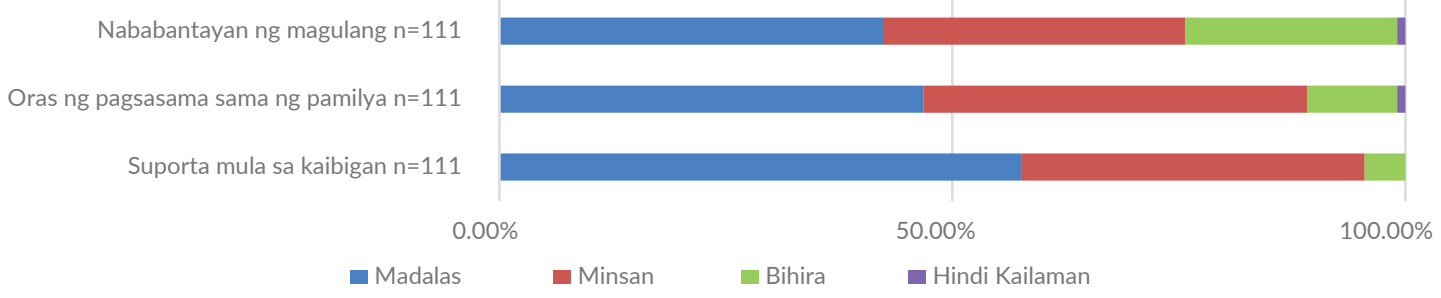

Figure 6. Distribution of social support of adolescents.

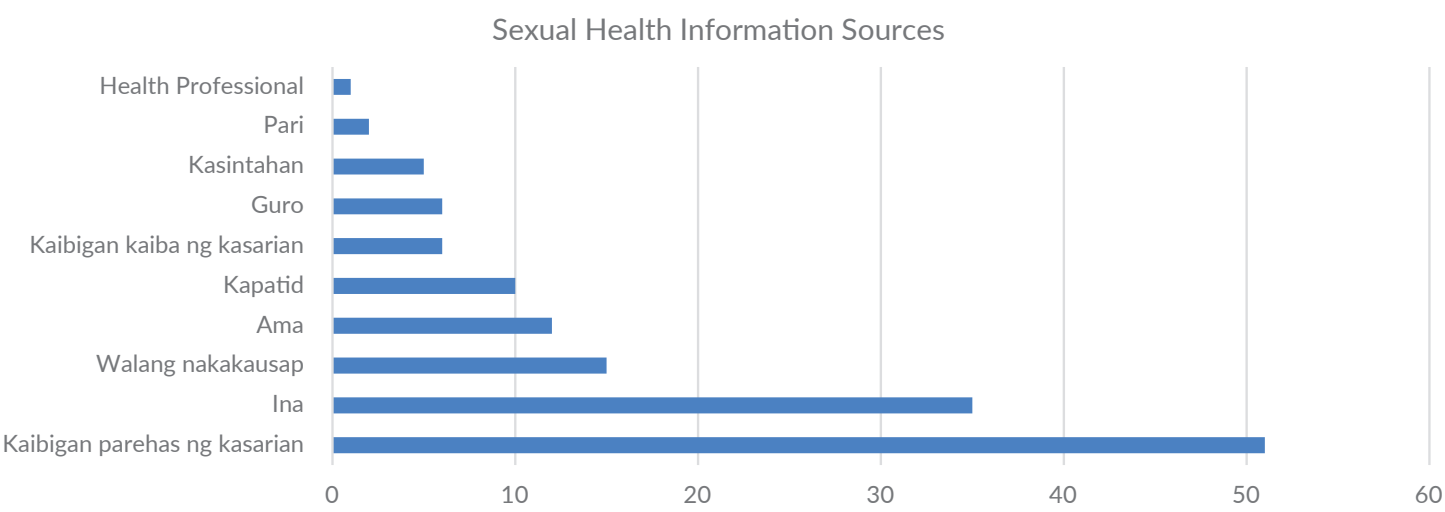

Figure 7. Sources of information on sexual health according to Grades 7-12 LBNHS students.

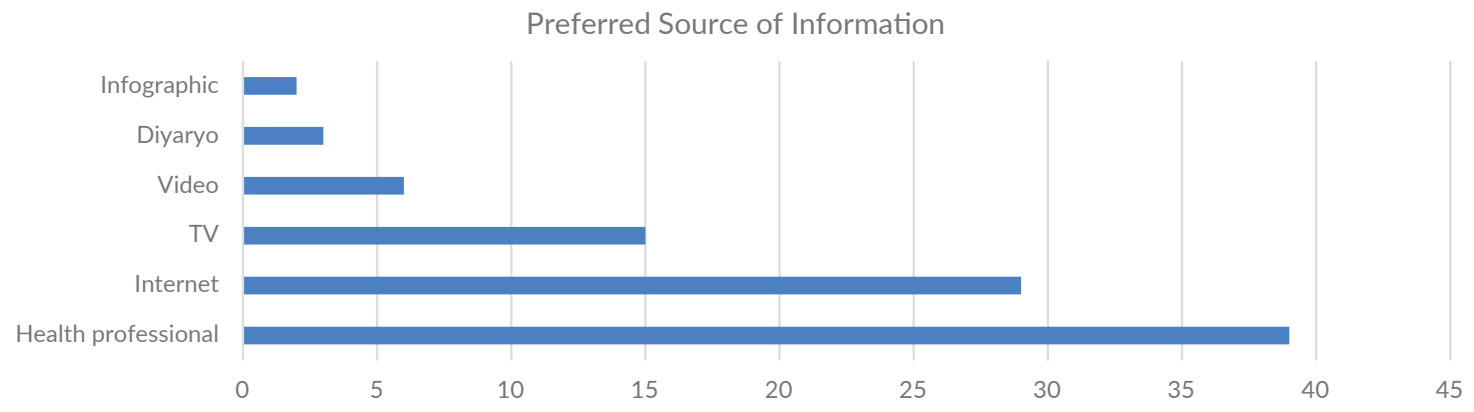

Figure 8. Preferred sources of information on sexual health according to Grades 7-12 LBNHS students. 


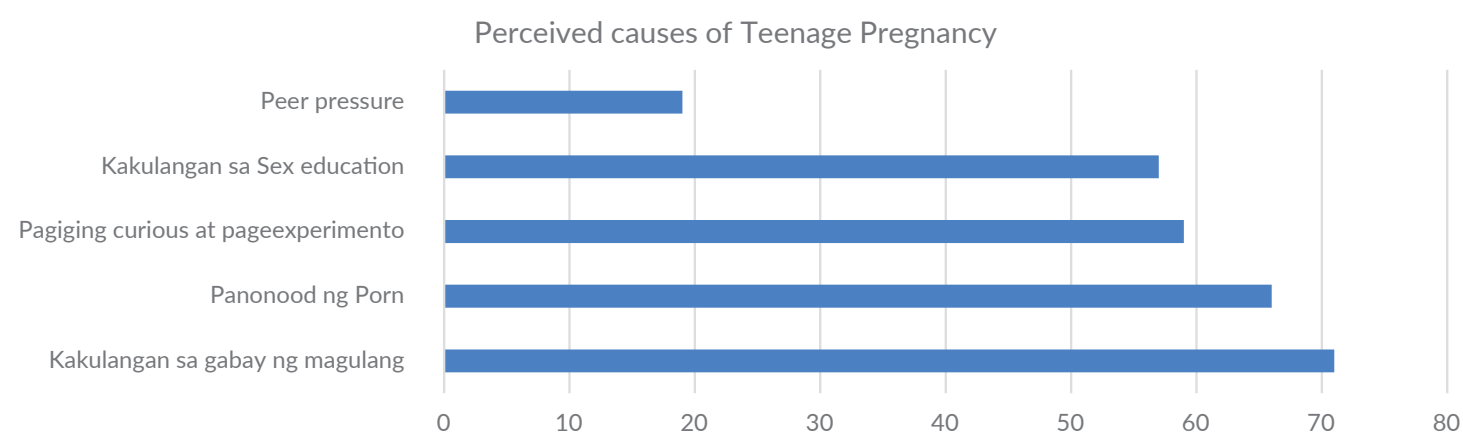

Figure 9. Perceived causes of teenage pregnancy of adolescents.

Knowledge about Sexual Health

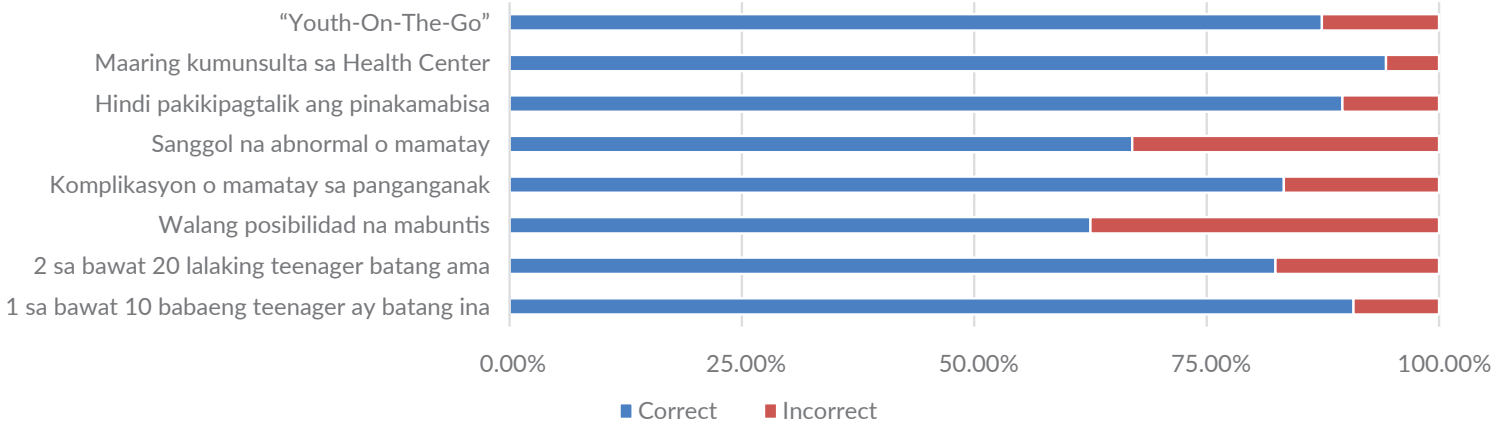

Figure 10. Knowledge on sexual health of Grades 7-12 LBNHS students.

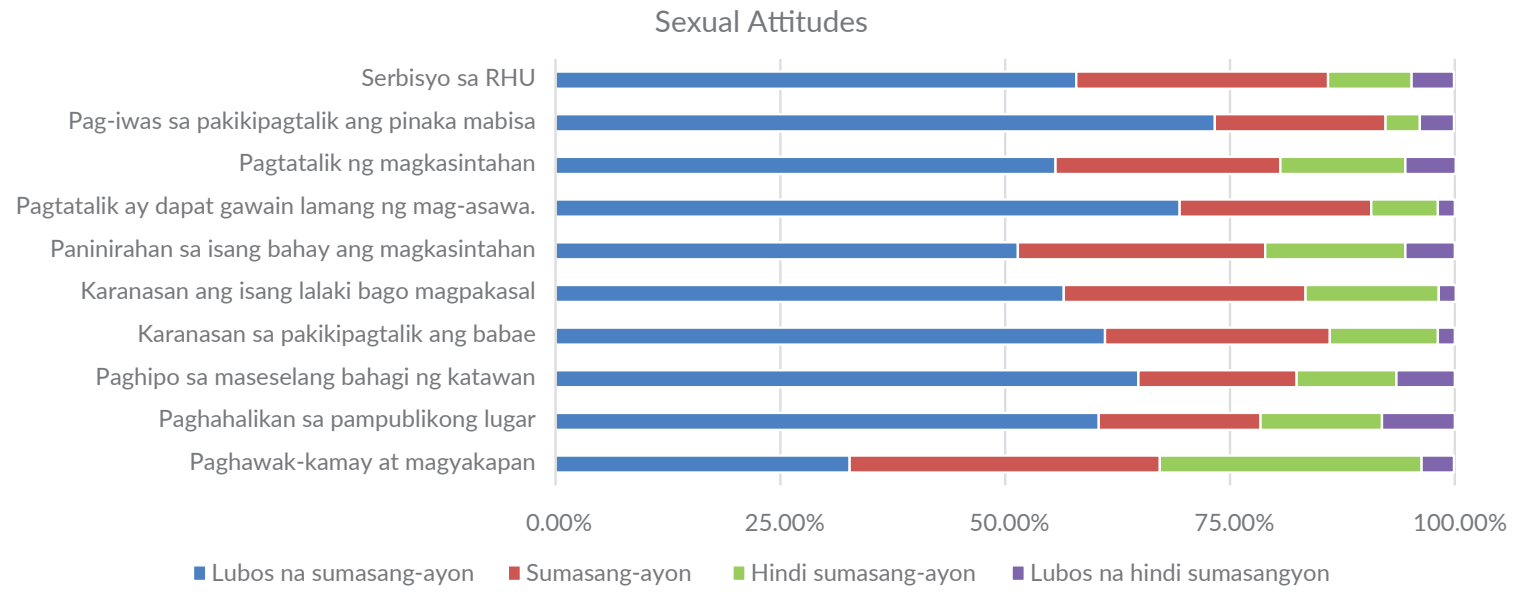

Figure 11. Sexual attitudes of Grades 7-12 LBNHS students.

\section{CONCLUSION AND RECOMMENDATIONS}

The knowledge, attitudes, and behavior of respondents do not generally suggest widespread premarital sexual practice. Approximately one-third of the respondents have misconception on the possibility of getting pregnant on first sexual contact and the concomitant risks to the infant brought about by teenage pregnancy. More than half of the respondents primarily refer to same-sex friends and secondly to their mothers on sexual health information which is consistent with Baheiraei (2014). ${ }^{5}$ Teenagers value the opinion of parents more than friends (Irala et al.,
2009). ${ }^{4}$ They prefer to receive sexual information from the doctors, parents, and peers (Castilla, 2001; YAFS, 2013).6,7 However, least information was received from healthcare professionals.

Internet and health professionals are preferred communication channels. The researchers were only able to reach 110 out of 359 target population and were only able to reach public school students. As recommended from the roundtable discussion during the validation meeting, collection of data should also be done for out-of-schoolyouth and private school students to increase generalizability of the findings. 


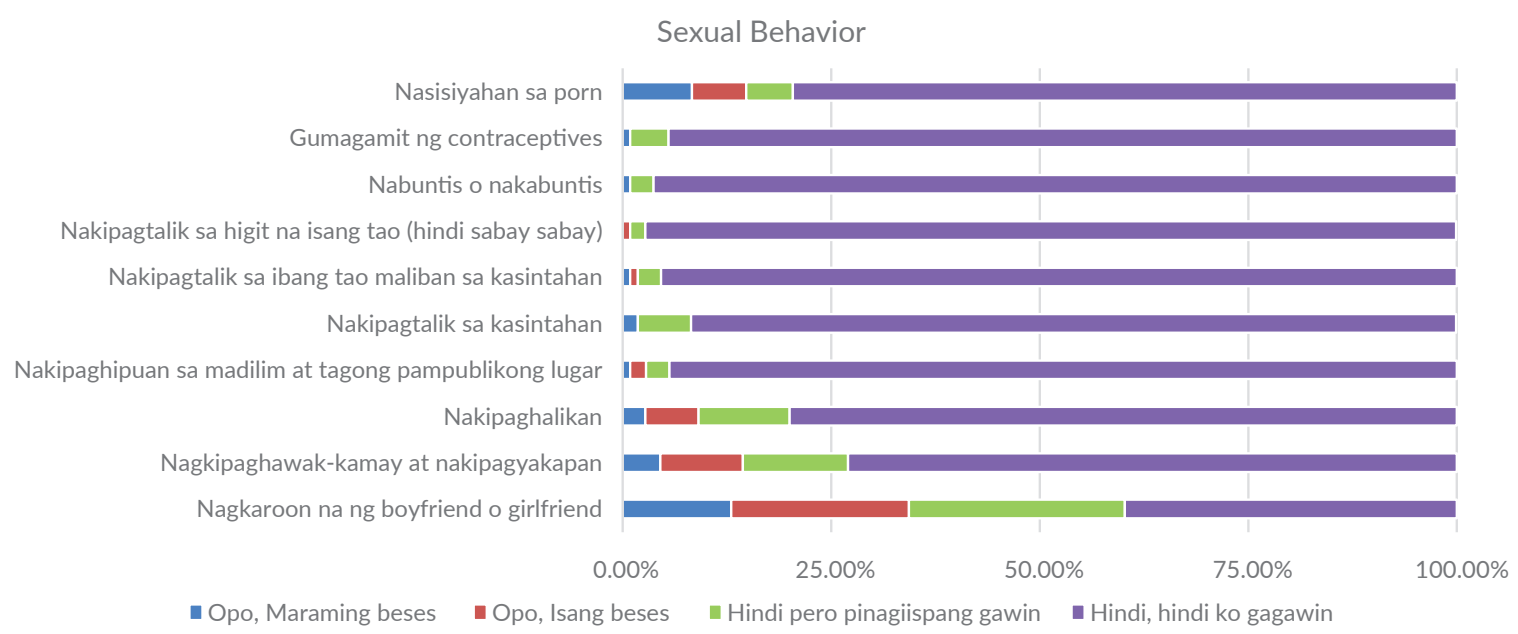

Figure 12. Sexual behavior of Grades 7-12 LBNHS students.

The validation roundtable discussion also yielded the following recommendations:

1. Utilize other forms of media such as TV and internet for health information dissemination. As seen from the $\mathrm{KAB}, 44 \%$ of the teenagers are accepting of sexual and health education through TV, video, and internet.

2. Increase the number of trained peer educators to include teachers as well. The KAB showed that while the most preferred source of sexual health information is "health professionals", the most common actual source of information is "friends of same sex". While it will take time and money to hire and deploy more health professionals to fill this unmet need, a fast and reliable alternative may be to involve teachers as substitutes for health professionals, especially if they are trained properly and endorsed by the health professional to the students (e.g. the $\mathrm{MHO}$ or PHN visiting classrooms and telling the students that they can talk to their teachers, as the MHO has trained the teachers accordingly).

\section{Acknowledgements}

The authors wish to thank Dr. Alvin Isidoro and Dra. Carlin Lawas-Fabian and the members of the Los Baños Rural Health Unit; in particular Dr. Alan Hostalero for providing opportunities on advocacy symposium and data collection with the assistance of Mr. Steven Aquino. We are also grateful for the strong commitment of Hon. Josephine Sumangil-Evangelista for organizing a successful sustainability program, as well as Ms. Karen Mercado, Gender and Development Head.

\section{Statement of Authorship}

All authors have approved the final version submitted.

\section{Author Disclosure}

Maria Eleanor L. Candelaria and Maricar B. Rodriguez share the main authorship. All authors declared no conflict of interest.

\section{Funding Source}

No external funding.

\section{REFERENCES}

1. Isidoro A. (June, 2018) Personal Interview.

2. Department of Health (DOH). Adolescent Health and Development Program Manual of Operations First Edition [Online] 2017. Available from:http://www.wpro.who.int/entity/philippines/publications/ adolescent_health_and_development_program_manual_of_ operations.pdf.

3. De Jose E. Filipino Adolescents' Sexual Attitudes and Behaviors: Results from a University Cohort. [Online] 2013. [cited Jun 2018] Available from Academic Journal of Interdisciplinary Studies. 10.5901/ ajis.2013.v2n8p719.

4. Irala J, Osorio A, Del Burgo C, et.al. (2009). Relationships, love and sexuality: what the Filipino teens think and feel. [Online]. 2009 [cited 2018 Jun] BMC Public Health 2009, 9:282. Available from http:// www.biomedcentral.com/1471-2458/9/282.

5. Baheiraei A, Khoori E, Foroushani AR, et al. (2014). What sources do adolescents turn to for information about their health concerns? [Online] 2014. [cited Jun 2018] Available from International Journal of Adolescent Medicine and Health 26(1):61-68. doi:10.1515/ ijamh.2012.0112.36.

6. Castilla R, Cerezo L, Estrada C. Adolescents and sources of sex information: preferences and perceived usefulness. [Online]. 2001 [cited 2018 Jun]. Available from https://www.ncbi.nlm.nih.gov/ pubmed/112189687.

7. Demographic Research and Development Foundation (DRDF) and University of the Philippines Population Institute (UPPI). (2014). 2013 YAFS4 Key Findings. Quezon City: DRDF and UPPI.

8. Nicolaos S. The "art" of questionnaire construction: some important considerations for manufacturing studies. Integrated Manufacturing Systems, 2003; 14:3. [Online] 2003. [cited Jun 2018] Available from: http://www.adolphus.me.uk/emx/surveys/pretesting.htm\#1.

9. Perneger T, Courvoisier D, Hudelson P, et.al . Sample size for pretests of questionnaires. [Online] 2014. [cited Jun 2018] Available from Quality of life research: an international journal of quality of life aspects of treatment, care and rehabilitation. 24. 10.1007/s11136-0140752-2. 